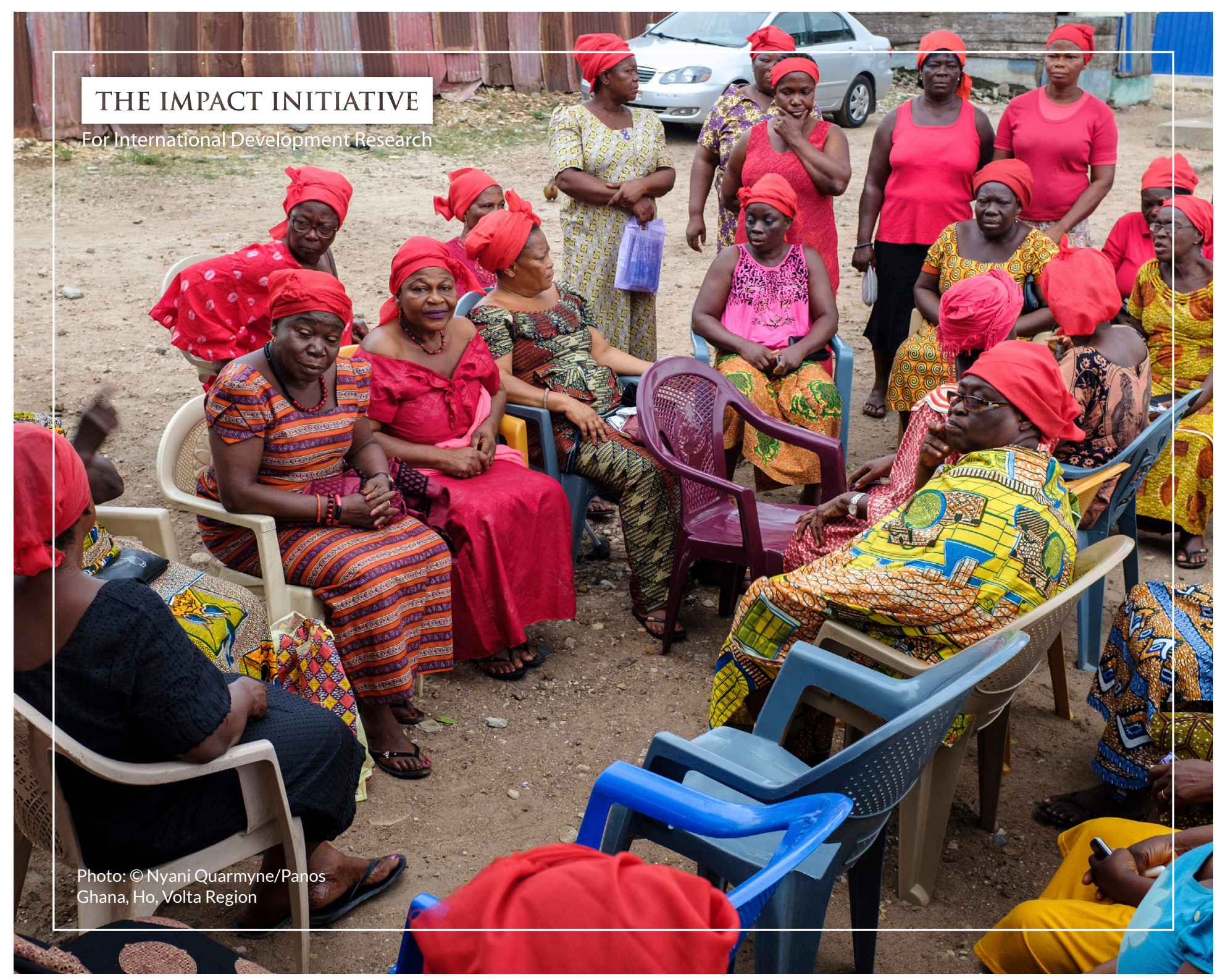

The Impact Lab // Learning Guides // Promoting non-academic engagement

\title{
Partnerships, Planning and Policy Windows: How to Engage Non-academics with International Development Research
}

\author{
Author: Sarah Nelson $\quad$ Published: November 2016
}

E.S.R.C
ECONOMIC
\&COCIAL
RESEARCH UKA
COUNCIL UKaid

Research jointly supported by the ESRC and DFID 


\section{THE IMPACT INITIATIVE}

For International Development Research

The Impact Lab presents a series of Learning Guides which draw on the lessons for successful impact from grants funded by the ESRC-DFID Joint Fund for Poverty Alleviation Research. The Joint Fund aims to enhance the quality and impact of social science research, with the goal of reducing poverty amongst the poorest countries and peoples of the world. Since 2005, the Joint Fund has enabled over 150 research projects.

An impact evaluation, undertaken in 2015 , assesses the impact of the first two phases of the Joint Fund, and provides a thorough assessment of impact on policymakers, and other stakeholders over the ten years since it began. The evaluation, published in 2016, identifies critical barriers to engagement and uptake in areas like networks and relationships, mutual learning, individual capacities and incentives and lack of demand for evidence. Drawing on the ESRC's conceptual framework for impact assessment to inform the evaluation methodology, the evaluation also recognises the complexities of the research to policy process and the multifaceted nature of social science impact.

The Impact Lab seeks to strengthen links and create dialogue by providing an outline of relevant issues and clear lessons for knowledge practitioners, funders and researchers. Each Learning Guide, therefore, identifies replicable approaches to effective engagement in a particular area previously identified by the impact evaluation as a potential barrier for impact. Drawing on diverse case studies from the first two phases of the Joint Fund, this learning guide shares the strategies that have been successfully employed by ESRC DFID grant holders to increase outreach and maximise research uptake and impact in these critical areas. Many of these approaches may require a better understanding of local conditions, more time, effort or funding. However, the results could significantly strengthen the efficacy of research projects' pathways to impact. 


\section{Introduction}

Many international development research projects aim to go far beyond influencing academic debate - they also seek to build relationships and networks, influence attitudes and behaviours, and inform policy and practice. Contributing to impacts of this kind (whether instrumental, conceptual, building capacity or strengthening networks ${ }^{3}$ ) requires engaging with a broad range of non-academic audiences.

\section{Which non-academic audiences might researchers engage with?}

- Policymakers - local, regional, national, international

- Non-Governmental Organisations (NGOs)

- Research subjects or beneficiaries

- Activists and campaigners

- Professional groups and associations

- Journalists and bloggers

- Local community groups and leaders

- Funders

- Parliamentarians and political stakeholders

- General public

However, engaging with non-academic audiences may be difficult for researchers. The targeted individuals or groups may be very different to the project team in terms of their knowledge, experience, priorities and working patterns. They may speak a different language. They may be based in a different location or be difficult to access or identify, with researchers rarely, if at all, crossing their paths. They probably do not attend academic conferences or read peer-reviewed journals, instead accessing information in different ways.

While a specific project or issue may be the primary focus for research teams, many nonacademic audiences are juggling other, conflicting priorities and working to much shorter timeframes. Different stakeholders may have different agendas - driven by a whole range of factors including organisational strategies, bureaucracy, political aims, personal ambitions, competing deadlines and constrained budgets .

\section{Why might it be difficult to engage with non-academic audiences?}

- Weak existing relationships with individuals or organisations

- Limited opportunities for networking or making contact

- Limited understanding of the audience's priorities and way of working
- Language, cultural or geographical barriers

- Lack of time to invest in developing relationships

- Lack of funding to develop audienceappropriate outputs

- Lack of incentive for engagement with a particular group 
This Learning Guide draws on lessons from four research projects funded by the UK's ESRC-DFID's Joint Fund for Poverty Alleviation Research:

- Children, transport and mobility in sub-Saharan Africa ${ }^{4}$ (2006-10, Principal Investigator: Dr Gina Porter, Durham University) which investigated mobility issues faced by children through child-centred research in Ghana, Malawi and South Africa. Prior to the study, there was a lack of evidence on the challenges faced by children on their journeys to school - such as dealing with wild animals, potential rapists and crossing dangerous streams during the wet season. The project had significant instrumental impact - for example, a new school was built for one community, and the teacher training curriculum in Ghana now includes information about child mobility issues. It also led to capacity building of the child researchers (many of whom have taken up tertiary education since the study).

- Community and institutional responses to the challenges facing poor urban people in an era of global warming in Bangladesh ${ }^{5}$ (2010-14, Principal Investigator: Professor David Hulme, University of Manchester) which explored climate change impacts and adaptation in poor urban settlements in Dhaka, Chittagong and Khulna. The projects investigated how climate change exacerbates existing challenges faced by poor urban people (such as scarce water supply, lack of sewerage and disrupted livelihoods), how people are adapting to these challenges from the ground-level up, and what policies or practices could support adaptation. The project saw improvements in policymakers' conceptual understandings of the issues and the findings may have acted as a catalyst for subsequent major improvements to drains and flooding infrastructure in settlements in two of the cities.

- Lone mothers in South Africa6 (2011-14, Principal Investigator: Professor Michael William Noble, University of Oxford) which investigated the role played by social security in respecting and protecting dignity for lone mothers in South Africa. The research was motivated by dependency-culture debates that were rife in South Africa, with lone mothers often being depicted by the media as lazy - yet while lone mothers may receive the Child Support Grant, they are not eligible for social assistance in their own right, unless they are disabled. The project helped to reframe negative debates in the media about social security and lone mothers.

- The development of migrant villages under China's rapid urbanisation: implications for poverty and slum policies ${ }^{7}$ (2010-12, Principal Investigator: Professor Fulong Wu, University College London) which examined the redevelopment of so-called urban villages in three major cities: Beijing, Shanghai and Guangzhou. The government wanted to redevelop and regenerate the informal settlements - which were crowded, with high crime rates and a lack of basic infrastructure - but needed to know the best approach to take. 
The research has contributed to policy change in Guangdong province, with development practice recently changing from demolition of the settlements to incremental changes with houses maintained to accommodate migrant workers (in line with the project's findings).

Engagement with non-academic audiences played a crucial role in generating impact in these four projects. Through studying the impact evaluation ${ }^{1}$ and interviews with the key researchers involved, The Impact Initiative identified ten practical steps that researchers can take to increase their capacity and capability to engage with non-academic audiences. In addition, two further suggestions are specified for research funders. These recommendations are set out in the next sections, along with practical examples from the four projects. 


\section{Top tips for researchers}

\section{Plan engagement from the start}

All the research teams had spent time analysing and planning for engagement with nonacademic audiences during the funding application and project inception phases. By investing time in identifying audiences, mapping networks and communications pathways, conducting any necessary research to understand the positionality of each audience and establishing key relationships at the beginning, researchers increased their knowledge exchange capacity.

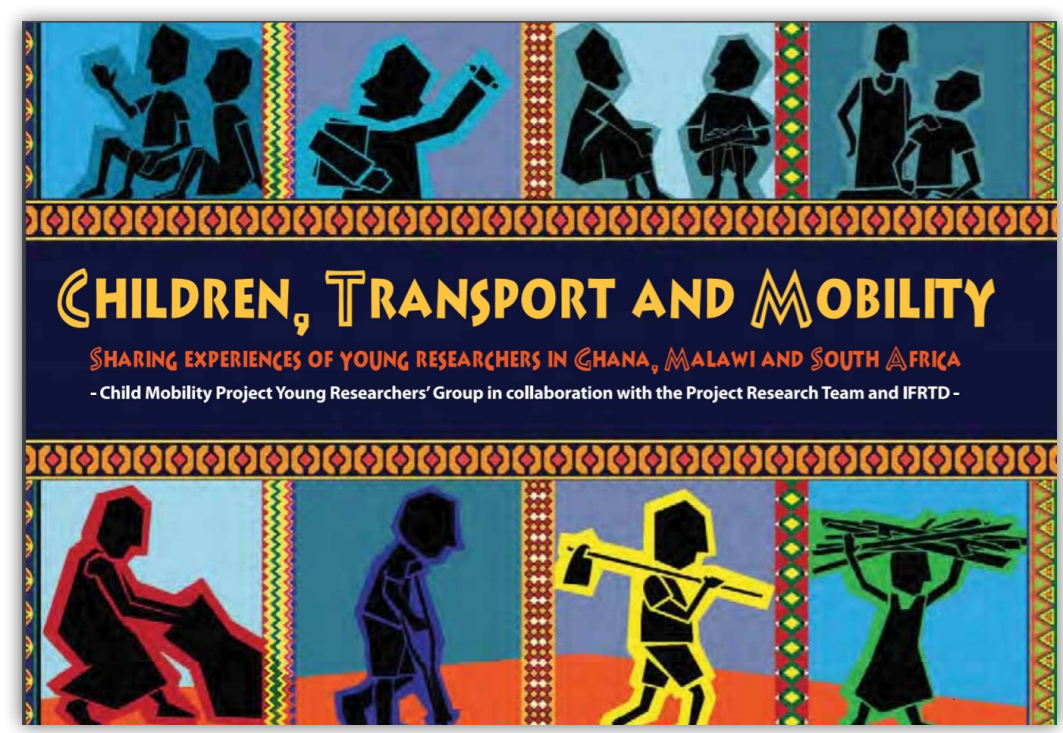

Additional funding was secured for child researchers involved in the Children, transport and mobility in sub-Saharan Africa project to publish a book (cover pictured above) which is available from University of Durham ${ }^{8}$.

\section{Example: Children, transport and mobility in sub-Saharan Africa ${ }^{4}$}

The project team carefully considered pathways to impact in the project design. Theresearchers knew from the start that they had to produce and present findings in clear understandable forms for specific non-academic audiences. Planning in this way certainly contributed to the project's significant impacton policy and practice. For instance, regular meetings with teachers and the Ghana Education Service in the project's Country Consultative Groups subsequently led to inclusion of information about child mobility issues in the teacher training curriculum. 


\section{Ensure engagement is structured and continuous}

All four studies engaged with non-academic stakeholders through a formal project advisory board or consultative group, which met regularly throughout the project's duration. Structured engagement in this way increases interest, encourages inclusivity and develops trust. Communication is two-way: a number of projects reported that the groups shaped their study's objectives and strategies.

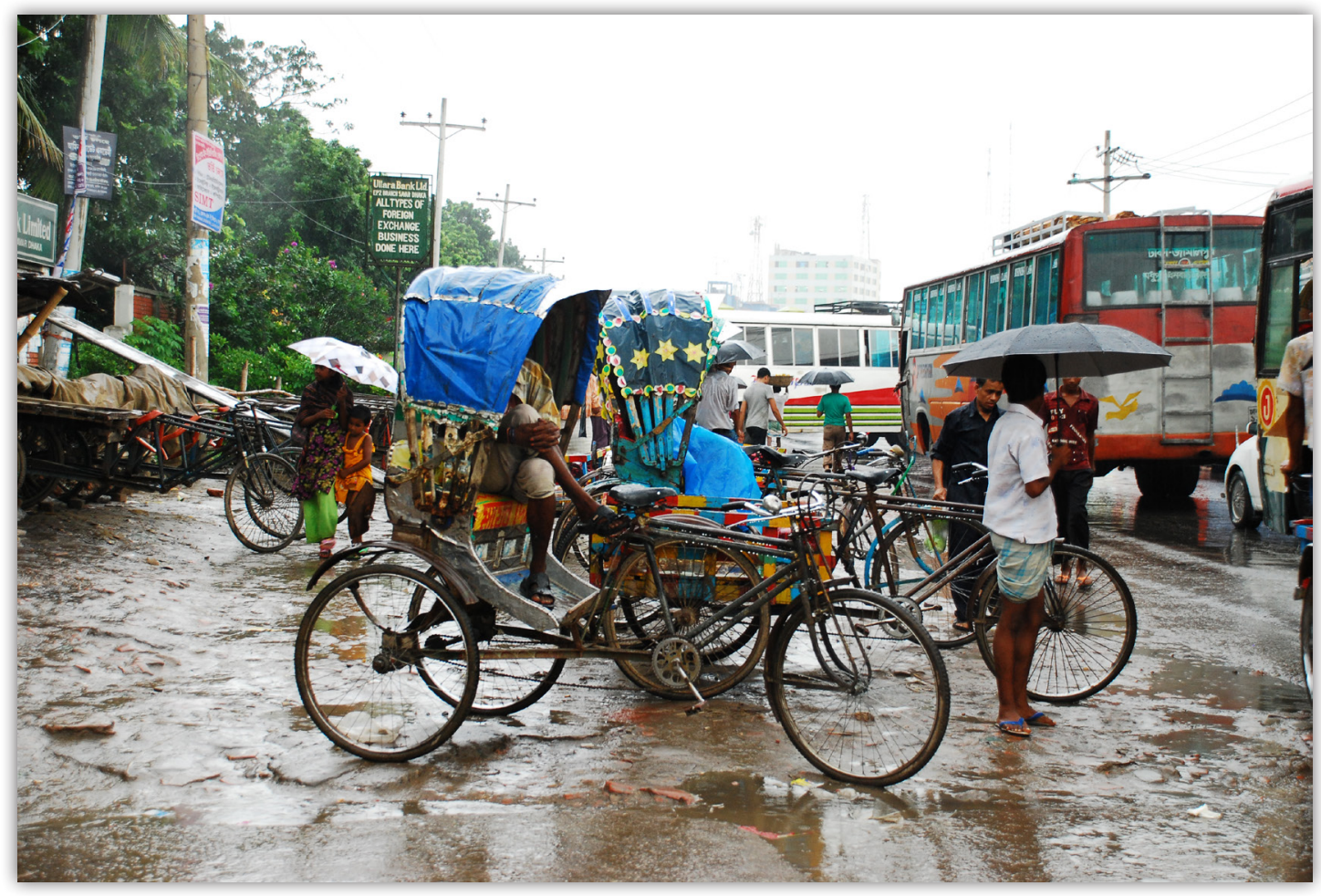

Sheltering from the storm, Bangladesh

Photo: Amir Jina/flickr licensed under CC BY-NC-ND 2.0

\section{Example: Lone mothers in South Africa ${ }^{6}$}

The researchers held an inception meeting at the start of the project, with non-governmental organisations (NGOs), national policymakers, members of provincial government and university colleagues. Some of these attendees became part of the advisory group, which met twice a year. If the group could not all travel to the samegeographical location (due to budgetary or diary constraints) then stakeholders joined the meeting virtually or were engaged through separate bilateral discussions. Dr Gemma Wright, the project's Co-Investigator, highlighted the benefit of involving stakeholders in this structured way: 'they can contribute to the way the project develops, so acquire a sense of ownership, and then interest in what the findings are.'

\section{'Structured engagement increases interest, encourages inclusivity and develops trust'.}




\section{Partner with non-academic actors to co-produce research}

Developing direct partnerships early-on with key non-academic stakeholders will ensure they are fully involved in the study, enabling a more inclusive research process. Some researchers saw particular audiences as co-investigators in the project, bringing in multiple perspectives to co-produce the research, rather than end-users of its findings.

\section{Example: Children, transport and mobility in sub-Saharan Africa ${ }^{4}$}

The International Forum for Rural Transport Development (IFRTD) is a global network of individuals and organisations improving access and mobility for rural communities in developing countries. Rather than categorising the IFRTD as one in a long list of stakeholders, the researchers directly partnered with the network from the start. This partnership provided invaluable information on the policy landscape and ensured the research was directly relevant to the network's strategy. It also aided dissemination of the project's findings - the IFRTD updated their 4000+ members regularly and highlighted the study in a special issue of IFRTD News sent to over 10,000 subscribers.

\section{4}

\section{Employ the most effective messenger}

Researchers should consider who the right people and groups are to reach particular non-academic audiences, paying attention to status, language and cultural considerations. Using a particular individual as a go-between or spokesperson may help hard-to-reach audiences to engage in the project. For example, national governments may be more attentive to in-country partners, and journalists may be more interested in hearing powerful stories from the research subjects or beneficiaries in their own words.

Example: Community and institutional responses to the challenges facing poor urban people in an era of global warming in Bangladesh ${ }^{5}$

The researchers found that high-level ministers and planners in Bangladesh were resistant to policy initiatives that tackled climate change challenges facing poorer people in cities, due to a persisting view that improving the lives of urban poor communities would intensify rural to urban migration. The team therefore worked directly with activist and advocacy groups, including grass-roots organisations, who are tackling this mind-set, feeding their findings into this movement. They were careful over their selection of these groups, ensuring they chose the mostconfidentand experienced organisations who had a history of influencing thegovernment. 


\section{Reach out to audiences in their own context}

Although it may not always be possible, there is value in arranging face to face meetings with stakeholders in their own locations. Rather than expecting people to come to a research centre or university, going directly to stakeholders can enhance engagement. One team visited many government, NGO and community offices, and also held events in a series of different locations, to suit different groups.

Example: The development of migrant villages under China's rapid urbanisation ${ }^{7}$

The researchers took advantage of field visits as an opportunity to keep local stakeholders informed on the progress of the research via face-to-face meetings. Principal Investigator Professor Fulong Wu commented, 'For policy, face-to-face contact is very useful. Policy briefs don't really have the same kind of effect as policymakers are very busy people.

\section{'For policy, face-to-face contact is very useful. Policy briefs don't really have the same kind of effect as policymakers are very busy people.' Professor Fulong Wu, University College London, Principal Investigator.}




\section{Ensure audiences feel involved and valued}

Many non-academic audiences will give up considerable amounts of time to engage with the research project, whether through attending meetings, workshops or being interviewed as part of the data collection process itself. Researchers should ensure audiences feel valued for their role in these activities.

Example: Community and institutional responses to the challenges facing poor urban people in an era of global warming in Bangladesh ${ }^{5}$

When reaching out to local communities, the team invited a local stakeholder to host the meeting. This gave them ownership of the discussion and allowed them to take credit for initiating something.

\section{7}

\section{Use the right tools and platforms for each audience}

Despite most researchers knowing that journal articles and conference presentations may not be the most effective ways to reach non-academic audiences, often too little time and budget is allocated to more appropriate communication tools. The projects found that policy briefings, media exposure, short practical guides or even the use of drama, visual arts and dance engaged their particular target audiences. Researchers should use suitable methods for each audience, taking professional advice where necessary, to ensure outputs use the right language and tone, appeal to audiences who may have little time to engage, and are accessible from the most effective platforms - on and offline. Funding for innovative non-academic outputs should be factored into the project's impact budget.

\section{Example: Children, transport and mobility in sub-Saharan Africa ${ }^{4}$}

One of the project's primary non-academic audiences was teachers and education professionals. To reach this audience, the researchers secured additional funding for the child researchers to publish a book (see page 6) giving them a voice. The children were involved in design and writing content during an international meeting and the book was distributed directly in schools and libraries across Ghana and Malawi, informing other communities of the mobility difficulties children face. 


\section{Identify and capitalise on policy windows}

Researchers should seize the opportunity to engage with policymakers on issues that are currently on their agenda, particularly when the political context is open to change. The majority of the studies recognised that policymakers were genuinely interested in their findings, and in one case they were writing directly relevant strategies during the project's lifecycle. If no obvious policy window exists, researchers should consider how to re-frame their findings to appeal to the interests of their audience or take part in initiatives that policymakers are already engaging in.

Example: The development of migrant villages under China's rapid urbanisation ${ }^{7}$ Through local knowledge and an in-depth understanding of the policy context from incountry partners, the research team were aware of interest from government in the subject of the study. This meant there was already a captive audience for the results, with Professor Fulong Wu, the project's Principal Investigator saying that, 'those in the policy field were looking for answers.' In terms of impact achieved, researchers saw a change in development of informal settlement practice in Guangdong province, consistent with the research findings. Although cautious to attribute policy change directly to the project alone, the researchers were confident that their work contributed to this shift.

\section{'If no obvious policy window exists, researchers should consider how to re-frame their findings to appeal to the interests of their audience.'}




\section{Utilise social networks and informal relationships}

Projects should make the most of the people or organisations with strong personal connections to their target audiences, in order to open doors and create opportunities for more formal engagement. Whether through extending hospitality or finding shared social connections and interests, researchers should not underestimate the value of informal relationships and hidden power. There is value in investing time at the start to map and understand the politics of the particular context within which the project is operating.

Example: Community and institutional responses to the challenges facing poor urban people in an era of global warming in Bangladesh ${ }^{5}$

The research team were well connected in Bangladesh and used their social networks with the policy elite to increase the project's impact. Professor David Hulme, the Principal Investigator, had a long-standing and familiar relationship with the Bangladeshi 'intelligentsia' explaining, 'They are my friends. I go out to dinner with them... it's very informal things, cups of tea and shared flights, but those are the people who are... talking in meetings and going to weddings with the minister.' The team also made the most of informal discussions at conferences and events. In one case, following informal discussions with the Minister of Finance, the team were invited to share their research with the Planning Commission, an organisation in a position to use the findings in decision-making.

\footnotetext{
'They are my friends. I go out to dinner with them... it's very informal things, cups of tea and shared flights, but those are the people who are... talking in meetings and going to weddings with the minister.'

Professor David Hulme, University of Manchester, Principal Investigator.
} 


\section{Ensure engagement is two-way}

Researchers should be receptive to requests for engagement in activities initiated by, or in the interests of, the target audience. Examples from the studies included taking on an advisory role with an NGO, attending meetings about national policy, and giving keynote speeches at professional conferences. Responding to such requests may be resource intensive, but it helps gain trust - and will ensure researchers better understand the audience's own perspective.

\section{Example: Lone mothers in South Africa ${ }^{6}$}

Co-Investigator Dr Gemma Wright highlighted the team's 'two-way mind-set', where stakeholders were seen as partners in, rather than recipients of, the research. For example, the team worked closely with the Chief of Social Policy at UNICEF South Africa, who described his mutually beneficial relationship with the project researchers... "We are finding a ... win-win situation, in which I really need [their] eyes and brains... and at the same time, we have organised some closed-door discussions with government on topics that are of concern to us." 


\section{Top tips for research funders}

Improving engagement with non-academic audiences also requires two clear actions on the part of research funders: time and money.

1

\section{Increase funding for non-academic engagement}

All four research projects highlighted the time it takes to engage with non-academic audiences, and three identified funding as a factor affecting their impact. Impact takes time, and may be difficult to clearly report on within the timeframe dictated by research funders. One researcher emphasised the time it takes to build relationships with new audiences, explaining that the project's duration (usually two or three years) may be too short to see tangible results from these relationships. Researchers particularly highlighted the difficulty in continuing to engage with non-academic audiences after the funding period is complete. All impact activity is then unfunded, which poses a challenge for staff who have new commitments. In one case, the Principal Investigator explained the pressure put on smaller in-country partners after the project's closure: 'Partners don't have the time to follow-up on impact themselves - whether carrying out new activities to reach the target audience, or gathering evidence to evaluate the impact of these activities.'

Developing innovative and targeted tools to engage non-academic audiences may require additional funding. Some projects had to turn elsewhere in order to fund outputs to reach particular audiences. Research donors could offer increased funding pots for innovative communication activities that develop during the project's duration (without requiring a new, time-consuming funding application) in order to give researchers the flexibility they need. Research funders should also consider allocating impact-related funding far beyond the project's official closure - as ESRC has done through Impact Acceleration Accounts (IAA) which are block awards made to research organisations to accelerate the impact of research. The IIA scheme is designed to respond (flexibly and rapidly) to support knowledge exchange activities in key areas including building relationships and networks and improving engagement with nonacademic actors (such as the public sector, civil society, industry, and the public). Following a pilot phase (in 2013-2014), ESRC DFID's Impact and Engagement Scheme 2015 has also provided follow on funding to researchers funded within Phase 2 of the Joint Fund. The scheme is designed to enable researchers to respond to emerging opportunities for knowledge exchange and research impact.

A small budget (for time and resources) that reduces incrementally over perhaps a three- to five-yearperiodmayincreasetheresearchers'capacitytoengagewithdifferentstakeholders. 


\section{Design funding calls to encourage partnerships with non-academic} stakeholders

Establishing partnerships with non-academic actors at the start of the four projects proved incredibly useful in fostering engagement and a more collaborative approach to research design and delivery. Research funders should encourage nonacademic stakeholders such as NGOs and the private sector to co-bid for research programme funding, alongside traditional academic actors. This would ensure partnerships are embedded from the start, enabling new audiences to be involved in the whole project's lifecycle - from research design through to dissemination. ESRC DFID encourage engagement with non-academics by allowing the inclusion of non-academics as co-investigators on grants enabled by the Joint Fund. An example of a project that does exactly this is the Measuring complex outcomes of environment and development interventions project ${ }^{9}$ which aimed to improve policies and practices in the environment-development sector. The project brought together the Wildlife Conservation Society (WCS) (https://www.wcs.org/) - an environmental organisation with programmes in 60 countries - with academics and other partners, to identify ways to assess the human wellbeing impact of environment-development activities and to encourage their adoption by practitioners and funders.

\section{'Research funders should encourage non-academic stakeholders such as NGOs and the private sector to co-bid for research programme funding, alongside traditional academic actors'.}




\section{Spotlight}

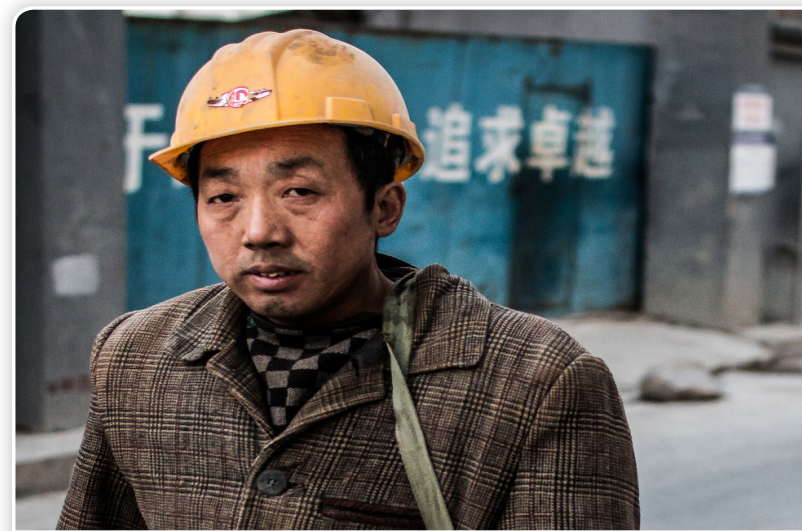

The development of migrant villages under China's rapid urbanisation: implications for poverty and slum policies ${ }^{7}$

The development of migrant villages under China's rapid urbanisation: implications for poverty and slum policies research project focused on influencing policy from the very start. The team recognised that engagement with nonacademic audiences would prove essential for the project's success, and employed a range of strategies and tools that contributed to policy impact.

Migrant worker, China

Photo: Matt Ming/flickr licensed under CC BY 2.0

\section{The challenge}

China has seen rapid urbanisation in recent years, with more than half of the population now living in cities and towns. Millions of rural migrants have found affordable homes in informal settlements, so-called 'urban villages'.

These settlements, which can be viewed as slums according to the UN-HABITAT definition, have become a significant issue for Chinese policymakers as they appear at odds with China's globalised image. In the suburbs of Beijing, former villages are turned into migrants' production sites; in the peri-urban areas of Shanghai, co-renting in the same room has become highly controversial; in Guangzhou, urban villages are becoming a 'thriving' world of their own, lacking basic infrastructure.

In 2010, policymakers were seeking an answer to these problems. Fulong Wu, Bartlett Professor of Planning at University College London, explains the policy window of opportunity that his team identified. 'There was a tension; the government wanted to redevelop these areas and upgrade the cities, but they also needed a cheap environment in which migrants could live. They wanted to know how best to do this.'

\section{The solution}

The team developed a research project to find a common solution, sampling 20 migrant villages in three major cities, identifying the housing tenure, socioeconomic profiles, landlords' self-construction tactics, migrants' coping strategies, and existing and new institutions as appropriate vehicles for in-situ redevelopment. 
The researchers identified a range of non-academic audiences to engage with, including Chinese national and city policymakers, DFID and its China office, the private sector, UN-HABITAT and the migrants living in the villages.

The team started planning their engagement with these stakeholders through field visits and consultation with local researchers and policymakers. They also established an impact advisory board at the project design stage, to provide a structured forum for feedback and engagement. Policymakers were seen as direct partners in the project from the beginning, rather than end-users of the research findings. Fulong Wu describes the care they took in managing this relationship: 'We came as open-minded researchers - not to criticise, but to find constructive solutions together.'

The choice of research partners was important too, because the in-country collaborators already had very close relationships with the policy circle. They served as a bridge between the UK-based research team and the local policymakers. 'When you have someone to introduce you into the circle, then they are more likely to trust you,' Fulong Wu explains. The team were also careful to reciprocate and engage in activities that were on the policymakers' agenda. For example, Fulong Wu was invited to give a keynote speech to the Urban Planning Society of China in 2013 attended by 6,000 people, and took a number of government advisory roles.

The researchers used a range of tools to reach out to the policy audience, including faceto-face meetings, training events, social media and a series of articles published in the China Daily newspaper. They also developed a regeneration handbook, setting out the research findings in a practical format for planners.

Outreach of this kind took a considerable amount of the team's time. Fulong Wu recognises that more skilled communications support would have been helpful, saying that 'additional funding would definitely have helped us to generate further impacts.' 


\section{The outcome}

The project has seen capacity-building impact amongst Master's students at Chinese universities who have begun to visit informal settlements and to consider different approaches to planning in these villages. There is also evidence of conceptual impact, with Fulong Wu being appointed by the Mayor of Guangzhou to serve as an advisory member of his Town Planning Board, for example.

Zhigang Li, the project's Co-Investigator explained the study's instrumental impact.

\section{'The project impact is quite obvious in Guangzhou. Historically, typical practice was to destroy these migrant villages. But now the strategy is changing gradually and a new one is being developed, and it is more tolerant towards these villages. It looks like the demolition of the villages has stopped'.} Professor Zhigang Li, Sun Yat-sen University, Co-Investigator.

While avoiding the claim of a direct causal link between the research and this new approach in Guangzhou, there is confidence that the project has contributed towards policy change. The team plans to do more to see their findings put into practice, and is actively seeking funding for a pilot scheme to test their recommendations.

Find out more about the project at www.urban-china.org

Professor Fulong Wu, University College London won the ESRC Celebrating Impact

Prize for Outstanding International Impact in 2013.

- Watch the video presenting Professor Fulong Wu's work on YouTube: https://www. youtube.com/watch?v=N03-CIRfxOI

- Find out more about ESRC's Celebrating Impact Prize: http://www.esrc.ac.uk/ research/celebrating-impact-prize/ 


\section{Conclusion}

For many international development researchers, engaging with non-academic audiences is not an optional activity that can be bolted on to the end of their study; instead it is a necessity that is crucial if their project is to achieve its objectives.

From establishing structured engagement groups and partnerships, to making the most of informal relationships and framing research to fit external policy windows, this Learning Guide has set out simple steps that researchers can take to increase their capacity and capability to engage with audiences such as policymakers, NGOs, local communities or the media. Context is everything and research teams should tailor their approach to the situation they face.

Setting up the right strategies and tools may appear a daunting task, particularly to researchers whose expertise lies mainly in their field of academic excellence. Where the project team lack the skills or experience they need, they should draw on the wealth of advice that is readily available - from experienced researchers, relevant literature, research funders, partners and knowledge exchange practitoners, or communications professionals - to maximise the impact of their engagement.

\section{References and key resources}

\footnotetext{
${ }^{1} 2016$ Impact evaluation of the Joint Fund: http://www.theimpactinitiative.net/2016-impactevaluation-joint-fund

${ }^{2}$ ESRC What is Impact? http://www.esrc.ac.uk/research/impact-toolkit/what-is-impact/

${ }^{3}$ ESRC-DFID Joint Fund for Poverty Alleviation Research: Guiding principles on uptake, impact and communication of research. http://www.esrc.ac.uk/files/research/international/guidingprinciples-on-uptake-impact-and-communication/
}

${ }^{4}$ Children, transport and mobility in sub-Saharan Africa (2006-10, Principal Investigator: Dr Gina Porter, Durham University). http://www.theimpactinitiative.net/project/children-transport-andmobility-sub-saharan-africa-developing-child-centred-evidence-base

${ }^{5}$ Community and institutional responses to the challenges facing poor urban people in an era of global warming in Bangladesh (2010-14, Principal Investigator: Professor David Hulme, University of Manchester). http://www.theimpactinitiative.net/project/community-andinstitutional-responses-challenges-facing-poor-urban-people-era-global-warming

${ }^{6}$ Lone mothers in South Africa (2011-14, Principal Investigator: Professor Michael William Noble, University of Oxford). http://www.theimpactinitiative.net/project/lone-mothers-south-africarole-social-security-respecting-and-protecting-dignity 
7 The development of migrant villages under China's rapid urbanisation: implications for poverty and slum policies (2010-12, Principal Investigator: Professor Fulong Wu, University College London). http://www.theimpactinitiative.net/project/development-migrant-villages-underchinas-rapid-urbanization-implications-poverty-and-slum

${ }^{8}$ No 10: Children, transport and mobility: Sharing experiences of young researchers in Ghana, Malawi and South Africa - Child Mobility Project Young Researchers' Group in collaboration with the project Research Team and IFRTD. https://www.dur.ac.uk/resources/child.mobility/children_ mobility_book_webversion.pdf

\section{Key resources}

Research funding and guidance:

- $\quad$ ESRC DFID Joint Fund for Poverty Alleviation Research Programme: http://www.esrc.ac.uk/research/international-research/international-development/esrcdfid-joint-fund-for-poverty-alleviation-research/

- $\quad$ ESRC DFID Raising Learning Outcomes in Education Systems Research Programme: http://www.esrc.ac.uk/research/international-research/international-development/esrcdfid-raising-learning-outcomes-in-education-systems-research-programme/

- $\quad$ ESRC Funding - information about funding opportunities and related guidance: http://www.esrc.ac.uk/funding/

- $\quad$ ESRC Impact Acceleration Accounts:

http://www.esrc.ac.uk/funding/funding-opportunities/impact-acceleration-accounts/

- $\quad$ ESRC Impact Prize:

http://www.esrc.ac.uk/research/celebrating-impact-prize/

- $\quad$ ESRC Research Funding Guide - May 2016

http://www.esrc.ac.uk/files/funding/guidance-for-applicants/research-funding-guide/

Tools and guidance for building impact:

- $\quad$ DFID Research Uptake Guidance - published May 2013 (updated April 2016): https://www.gov.uk/government/publications/research-uptake-guidance

- $\quad$ ESRC Developing impact evaluation: http://www.esrc.ac.uk/research/research-and-impact-evaluation/developing-impactevaluation/

- ESRC DFID Joint Fund for Poverty Alleviation Research - Impact and Engagement scheme 2015 http://www.esrc.ac.uk/funding/funding-opportunities/esrc-dfid-impact-and-engagementscheme-2015/ 
- $\quad$ ESRC Impact Case Studies:

http://www.esrc.ac.uk/news-events-and-publications/impact-case-studies/

- $\quad$ ESRC Impact Toolkit: provides definitions of impact; guidance and support for maximizing research impact; for 'Developing Your Pathway to Impact' (http://www.esrc.ac.uk/research/ impact-toolkit/developing-pathways-to-impact/); and includes a variety of communications tools for developing effective research communications:

http://www.esrc.ac.uk/research/impact-toolkit/

- $\quad$ ESRC 'Pathways to Impact for Je-S (Joint Electronic Submission System) applications guidance for applicants:

http://www.esrc.ac.uk/funding/guidance-for-applicants/je-s-electronic-applications/ pathways-to-impact-for-je-s-applications/

- The UK Collaborative on Development Sciences (UKCDS): provide a useful guide on Finding and Building Effective Partnerships (http://www.ukcds.org.uk/resources/finding-andbuilding-effective-partnerships) along with a range of resources on relationship building and collaborative working: http://www.ukcds.org.uk/resources

Further resources:

- $\quad$ Evaluating the Impact of the ESRC-DFID Joint Fund for Poverty Alleviation Research: Final report to ESRC and DFID (March 2016)

http://www.esrc.ac.uk/files/research/research-and-impact-evaluation/evaluating-theimpact-of-the-esrc-dfid-joint-fund-for-poverty-alleviation-research/

- $\quad$ Related to this report: The Joint Fund for Poverty Alleviation Research impact evaluation: a response from ESRC and DFID (March 2016):

http://www.esrc.ac.uk/files/research/research-and-impact-evaluation/joint-fund-forpoverty-alleviation-research-impact-evaluation-a-response-from-dfid-and-esrc/

- Policy, practice and business impacts: evaluation http://www.esrc.ac.uk/research/research-and-impact-evaluation/policy-practice-andbusiness-impacts-evaluation-studies/ 


\section{Capacity Building*}

Through technical and personal skill development

\section{Co-construction (of knowledge)}

An approach to learning in which the focus is on collaborating with others in order to build a body of knowledge and understanding that is shared by everyone in the group - individuals are actively involved in the process of developing understanding as equal partners.

\section{Co-learning}

Collaborative learning in which individuals come together (either as pairs or as a larger group) to capitalize on one another's experience, skills, and perspectives in order to develop a common understanding.

\section{Co-production}

Collaborative and reciprocal process by which individuals design, develop and deliver a product (the research, or research outputs such as a publication, event or workshop) through equal partnership.

\section{Communication pathways}

A method or strategy that engages those with knowledge and ensures that information is effectively communicated to a wider audience.

\section{Communities of Practice (CoP)}

Where individuals interact as a group around a common theme, topic or body of knowledge in order to exchange learning and understanding. Online Communities of Practice can be useful forums of peer support, particularly when individuals are spread geographically.

\section{Conceptual*}

Contributing to the understanding of policy issues, reframing debates

\section{Cumulative influence*}

Research impact and influence that emerges over a longer period of time as evidence and debate increases, grows and deepens.

\section{Instrumental *}

Influencing the development of policy, practice or service provision, shaping legislation, altering behaviour

\section{Knowledge broker}

"A knowledge broker is an intermediary (an organization or a person), that aims to develop relationships and networks with, among, and between producers and users of knowledge by providing linkages, knowledge sources, and in some cases knowledge itself..." (Wikipedia)

\section{Knowledge exchange}

Knowledge exchange is a process that brings all stakeholders together (i.e. researchers, research users, policy-makers, and communities) in order to exchange expertise, information, ideas, experience and to learn from learning emerging from research.

\section{Knowledge exchange capacity}

Developing the skills and ability to foster knowledge exchange.

\section{Knowledge intermediaries}

The knowledge intermediary role is to bring producers and users of knowledge together therefore helping to connect evidence with demand.

\section{Mutual learning}

Process of collaborative learning between two or more individuals. A broad definition of mutual learning in a research context would include all stakeholders being engaged in collective learning from research from the outset and continuously throughout in order to benefit the development of the research and support its' medium to longer term impact and sustainability. Mutual learning can also be applied to the communication and dissemination of lessons learnt to a wider audience.

\section{Outputs}

Outputs are related more to the immediate results of research in terms of what was produced or undertaken.

\section{Outcomes}

Outcomes are the consequences of research in the medium to longer term.

${ }^{*}$ These definitions are drawn from the following resources:

- What is impact? The Economic and Social Research Council (ESRC) Toolkit

- Evaluating the Impact of the ESRC-DFID Joint Fund for Poverty Alleviation Research. 


\section{THE IMPACT INITIATIVE}

For International Development Research

The Impact Initiative for International Development Research exists to increase the uptake and impact of two programmes of research funded through the ESRC-DFID Strategic Partnership. These are: (i) The Joint Fund for Poverty Alleviation Research, and (ii) The Raising Learning Outcomes in Education Systems programme. The Initiative helps identify synergies between these programmes and their grant holders, and supports them to exploit influencing and engagement opportunities and facilitates mutual learning.

The Impact Initiative is a collaboration between the Institute of Development Studies (IDS) and the University of Cambridge's Research for Equitable Access and Learning (REAL) Centre.

www.theimpactinitiative.net

All content is available under the Open Government License v3.0, except where otherwise stated.
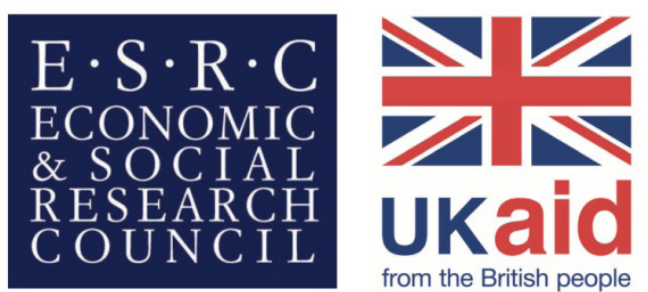

Research jointly supported by the ESRC and DFID 